\title{
Increased Work Experience Associated with Less Stigmatizing Attitudes towards People Living with HIV among Thai Healthcare Personnel
}

\author{
Kriengkrai Srithanaviboonchai ${ }^{1,2, *(\mathbb{D})}$, Porntip Khemngern ${ }^{3}$, Jarun Chuayen ${ }^{2}$ and Taweesap Siraprapasiri ${ }^{3}$ \\ 1 Faculty of Medicine, Chiang Mai University, 110 Intavaroros, Sriphum, Muang, Chiang Mai 50200, Thailand \\ 2 Research Institute for Health Sciences, Chiang Mai University, 110 Intavaroros, Sriphum, Muang, \\ Chiang Mai 50200, Thailand; nui.jk17635@gmail.com \\ 3 Department of Disease Control, Ministry of Public Health, 88/21 Tiwanon Road, Thaladkwan, Muang, \\ Nonthaburee 11000, Thailand; itimpornt@yahoo.com (P.K.); taweesap@rocketmail.com (T.S.) \\ * Correspondence: kriengkrai@rihes.org; Tel.: +66-5394-6148
}

Citation: Srithanaviboonchai, K.; Khemngern, P.; Chuayen, J.; Siraprapasiri, T. Increased Work Experience Associated with Less Stigmatizing Attitudes towards People Living with HIV among Thai Healthcare Personnel. Int. J. Environ. Res. Public Health 2021, 18, 9830. https://doi.org/10.3390/ ijerph18189830

Academic Editors: Carl A. Latkin and Zahid Ahmad Butt

Received: 12 August 2021

Accepted: 13 September 2021

Published: 18 September 2021

Publisher's Note: MDPI stays neutral with regard to jurisdictional claims in published maps and institutional affiliations.

Copyright: (c) 2021 by the authors. Licensee MDPI, Basel, Switzerland This article is an open access article distributed under the terms and conditions of the Creative Commons Attribution (CC BY) license (https:// creativecommons.org/licenses/by/ $4.0 /)$.

\begin{abstract}
HIV-related stigma in health facilities has been suggested as a primary target for HIV-related stigma reduction. The objective of this study was to describe negative attitudes among Thai healthcare personnel (HCP) toward PLHIV. This nationwide probability sampled survey was conducted in 2019 in 12 provinces in Thailand and Bangkok, the capital. Participants were considered to have stigmatizing attitudes toward PLHIV if they had a stigmatizing view in response to at least one of the four questions. Eighty-two percent of the 3056 respondents had at least one stigmatizing attitude. Younger HCP, ages < 30 (AOR = 1.60; 95\%CI: 1.18-2.18) and 30-39 (AOR = 1.60; 95\%CI: 1.21-2.12) were more likely to have stigmatizing attitudes towards PLHIV compared to those aged 50 and older. Being support staff, support-clinical (AOR $=1.89 ; 95 \% \mathrm{CI}$ : 1.44-2.49) and support-nonclinical $(\mathrm{AOR}=1.71 ; 95 \% \mathrm{CI}: 1.24-2.36)$ as opposed to professional staff also increased the likelihood of having stigmatizing attitudes. Stigma was also more likely to be present in HCPs who did not work at HIV-focused clinics (AOR = 1.97; 95\%CI: 1.57-2.48). HCP who had more work experience, especially related to PLHIV care, were less likely to have stigmatizing attitudes. These personnel could be good peer educators or role models for a stigma reduction campaign within their healthcare facilities.
\end{abstract}

Keywords: HIV-related stigma; healthcare personnel; negative attitude; Thailand

\section{Introduction}

HIV-related stigma has been widely cited as a major obstacle in reaching global targets to ending the AIDS epidemic [1-4]. The United Nations Joint Program of HIV/AIDS (UNAIDS) defines HIV-related stigma and discrimination as: "a 'process of devaluation' of people either living with or associated with HIV and AIDS Discrimination follows stigma and is the unfair and unjust treatment of an individual based on his or her real or perceived HIV status" [5]. While PLHIV face discrimination in many areas of their lives, HIV-related stigma associated with health facilities is particularly concerning as these venues play a crucial role in ending the AIDS epidemic. Consequently, health facilities have been identified as primary targets for HIV-related stigma reduction [6].

Reported discriminatory practices by healthcare personnel (HCP) toward PLHIV and those perceived to be HIV-infected included humiliation and blame [7], refusal of care [7-9], physically labeling clients as HIV-positive [9], unnecessary referrals to other healthcare facilities [9], excessive precautions and physical distancing [7,9,10], suboptimal care [7], isolating patients for no sound medical reason [8], and testing for HIV or disclosing HIV status without consent $[9,10]$.

HIV-related stigma in healthcare settings compromises the effectiveness of HIV prevention and control programs in many ways. Research has found that persons who engaged in HIV risk behaviors were reluctant to take HIV tests and other preventive measures 
due to anticipation of discriminatory practices at health facilities [11-13]. Among known HIV-infected individuals, many have avoided or delayed antiretroviral treatment (ART) if they anticipated or perceived discriminatory practices at health facilities $[7,14,15]$. HIVinfected patients in care who faced discrimination from HCP were more likely to be lost to follow-up, possibly leading to poor medical adherence and virologic failure $[7,16,17]$.

There are three main causes of HIV-related stigma in health facilities: lack of awareness of what constitutes stigma and why it is problematic; fear of HIV infection due to incorrect knowledge about HIV transmission; and negative attitudes toward people living with HIV (PLHIV) [6]. They are recognized as actionable drivers of HIV-related stigma as they could be mitigated through proper interventions.

Of the three drivers of HIV-related stigma in health facilities, negative attitudes toward PLHIV are noteworthy and need to be emphasized. While lack of awareness of HIV-related stigma and unjust fear of HIV infection might simply be addressed through education and training, HCP negative attitudes toward PLHIV is more difficult to address. Socially, people associate HIV infection with behaviors perceived to be immoral or improper, namely promiscuous sex and illicit drugs use [18-20]. Several recent studies conducted in a variety of social and cultural contexts consistently described relatively high levels of stigmatizing attitudes toward PLHIV among healthcare providers [9,19-24].

Thailand has been admired by the international community for its achievements in tackling HIV/AIDS [25]. However, recent studies revealed that there are ongoing localized HIV epidemics in some key populations, especially men who have sex with men and transgender women [26-29]. In 2019, only $80 \%$ of people diagnosed with HIV received ART, below the national target of $90 \%$ [30]. This rate might be explained in part by HIVrelated stigma in Thai health facilities. Information on the details, extent, and determinants of stigmatization is needed to properly design targeted interventions for the country.

The literature on HIV-related stigma in Thai health facilities is scarce and outdated according to a recent published review article [31]. The Stigma Index Survey conducted in 2009 by the Thai Network of People Living with HIV / AIDS found that around $20 \%$ of PLHIV respondents had been refused health or dental care [32]. Burmese migrant workers who were also HIV infected reported discrimination from Thai HCP when seeking care and treatment due to their migrant status [33]. A study conducted among student nurses in Bangkok found that PLHIV were stigmatized but were significantly less stigmatized than intravenous drug users [34]. Thus far, there has been no research directly addressing stigmatizing attitudes toward PLHIV among Thai HCP.

As part of systematic efforts to measure and reduce HIV-related stigma [35], the country has established a national surveillance system to monitor HIV-related stigma in government health facilities. The tools used in this surveillance have been adapted from recommended global tools. The process of developing and standardizing these tools has been published elsewhere [36]. The objectives of this study were to quantify and describe negative attitudes among Thai HCP toward PLHIV as well as to identify the determinants of these negative attitudes using the data from the 2019 Thai national surveillance survey.

\section{Materials and Methods}

\subsection{Study Setting and Selection of Study Sites}

This cross-sectional survey study was conducted in 2019 as the core activity of Thailand's national surveillance system to monitor HIV-related stigma in government healthcare facilities. All provinces including Bangkok were eligible to be included in the study. Thirteen geographical areas, 12 provincial centers of Thailand's 12 health regions, plus the capital city of Bangkok, were then selected as the national surveillance sites. Apart from Bangkok, all provinces were purposively selected as the economic centers of each region and based on high HIV burden. The provinces represented were Chiang Rai, Phitsanulok, Nakhon Sawan, Saraburi, Nakorn Pathom, Chon Buri, Khon Kaen, Udon Thani, Nakorn Ratchasima, Ubon Ratchathani, Nakorn Si Thammarat, and Songkhla. The only province that was not the official center of its region was Chiang Rai, which was selected in place 
of Chiang Mai due to management issues. Within each province, all hospitals under the Office of Permanent Secretary, Ministry of Public Health, with HIV clinics were invited to participate in the survey. These included all regional, general, and community hospitals providing coverage for most of registered patients with PLHIV in their respective areas. For Bangkok, all hospitals under the Bangkok Metropolitan Administration were included in the study.

\subsection{Study Population}

All HCP who worked at these hospitals and provided direct services to patients and their relatives (regardless of patient HIV status) were eligible to participate in the study. These included both clinical and non-clinical staff. Staff who did not have direct contact with patients or their relatives (back-office staff), such as procurement, document, and personnel division staff were not eligible. The intention was to capture the perspectives of diverse hospital staff who may discriminate against PLHIV in the healthcare facilities.

\subsection{Sample Size Calculation and Sampling}

The sample size for each study area (12 provinces and Bangkok) was computed to estimate the level of HIV-related stigma in healthcare facilities at the provincial level. This was to make sure that each province had its own meaningful information for use. The sample sizes were calculated using the prevalence of stigmatizing attitudes among Thai HCP from an unpublished pilot study $(85.8 \%)$ based on an estimation of $p(p=0.858)$, at the $95 \%$ confidence level, and with a $10 \%$ acceptable error bound [37]. The final figures were increased by $10 \%$ to compensate for expected incomplete questionnaires. The sample sizes ranged from 182 (Chiang Rai) to 312 (Pitsanulok). The samples of all 13 study areas were then combined for a total study sample size (3056).

The sample size at each hospital was determined proportional to the number of healthcare staff of the whole province. The names of all eligible HCP at particular participating hospitals were compiled. Simple random sampling was used to draw up a list of potential participants who would be invited to participate in the survey.

\subsection{Measurements}

The survey included questions on participant demographics including gender, age, profession, geographical region, whether the participant worked at an HIV-focused clinic, and estimated number of PLHIV that the participants has provided care for during the last 12 months.

Professions were categorized into 3 groups: (1) Health professionals (medical doctor, dentist, nurse, pharmacist, laboratory technician, physical therapist, psychologist, social worker, and radiologist), (2) Support-clinical (nurse aide, dental assistant, pharmacy assistant, paramedic, health educator, hospital porter, laboratory assistant, and radiologic assistant), and (3) Support non-clinical staff (cashier, receptionist, cleaner, driver, waiter, administrative staff, security guard, and medical record staff).

The study sites (hospitals) were divided into 5 geographical regions: (1) northern (Chiang Rai and Phitsanulok), (2) central (Nakhon Sawan, Saraburi, Nakorn Pathom, and Chon Buri), (3) northeastern (Khon Kaen, Udon Thani, Nakorn Ratchasima, and Ubon Ratchathani), (4) southern (Nakorn Si Thammarat and Songkhla) and (5) Capitol (Bangkok).

Clinics focused on the following treatment areas were defined as HIV-focused clinics: antiretroviral (ARV) treatment, HIV counseling, antenatal care, sexually transmitted diseases, and tuberculosis. Participants working at these clinics were considered HIV-focused HCP.

Questions were adapted from global tools and standardized for the Thai context [32]. Four items were used to measure negative attitudes towards PLHIV: (1) "Women living with HIV should be allowed to have babies if they wish," (2) "People get infected with HIV because they engage in irresponsible/immoral behaviors," (3) "People living with HIV should be ashamed of their HIV status," and (4) "Most people living with HIV do 
not care that they could infect other people." The response choices were "Strongly agree", "Agree", "Disagree", and "Strongly disagree". The "Strongly agree" and "Agree" answers were grouped as "Agree". The "Disagree" and "Strongly disagree" answers were grouped and "Disagree". Participants who disagreed with question 1 or agreed to questions 2, 3, or 4 were considered to have negative attitudes toward PLHIV. The final composite variable of negative attitudes toward PLHIV was used as the main outcome of the study.

\subsection{Data Collection}

The survey was conducted from June to September 2019. The data collection team included local, provincial, and regional health officers. A centralized training was administered to the study team prior to the actual data collection. Potential participants who were randomly selected from eligible staff were asked to come to a hospital conference room, usually during lunchtime. For the hospitals that required large samples, these informational meetings were limited to 20 people at a time to allow participants to sit far apart to maintain privacy. Study staff informed potential participants about the objectives of the study, benefits and risks, and how long the questionnaire would take. Interested participants who were willing to participate provided signed informed consent, and then read and completed the questionnaire online by themselves using their own smart device. Study staff made individual appointments to speak with potential participants who were not available for the information sessions. If a potential participant was too busy or refused to participate, an alternate $\mathrm{HCP}$ was randomly selected from the roster as a replacement.

\subsection{Data Analysis}

Data were entered, cleaned, and analyzed using the Statistical Package for the Social Sciences (SPSS), version 22.0 (IBM Corporation, Armonk, NY, USA). Descriptive statistics included frequencies, percentages, and means where appropriate.

Odds ratios $(\mathrm{OR})$ were calculated to determine the relationships between the predictor variables (participant characteristics) and the outcome variable (composite variable of negative attitudes toward PLHIV). All predictor variables with significant relationships were included in the binary logistic regression analysis and the results were reported as Adjusted Odds ratios (AOR). A $p$-value $<0.05$ was considered statistically significant for all analyses.

\subsection{Ethical Consideration}

The study was approved by the Research Ethics Committee of Faculty of Medicine, Chiang Mai University (Certificate number 177/2019). Participation was voluntary, and all participants provided written informed consent prior to participation.

\section{Results}

\subsection{Participant Characteristics}

Of 3056 participants, $83.3 \%$ were female and the average age was 39.2 years old. Most were professional health staff (63.9\%), followed by support-clinical staff $(20.8 \%)$, and support-nonclinical staff $(15.0 \%)$. The largest group of participants were from the northeastern region (31.1\%) while the smallest group were from Bangkok $(7.3 \%)$. Regarding specialized care for PLHIV, only $21.9 \%$ worked at HIV-focused clinics and $21.2 \%$ had provided care for more than 20 PLHIV during the last 12 months (Table 1). 
Table 1. Characteristics of Thai Healthcare Personnel $(N=3056)$.

\begin{tabular}{lc}
\hline \multicolumn{1}{c}{ Characteristics } & $\boldsymbol{n}(\mathbf{\%})$ \\
\hline Gender & \\
Female & $2546(83.3)$ \\
Male & $508(16.6)$ \\
Did not answer & $3(0.1)$ \\
Age (years) (mean = 39.2, SD =10.1) & \\
$<30$ & $634(20.7)$ \\
$30-39$ & $904(29.6)$ \\
$40-49$ & $868(28.4)$ \\
$\geq 50$ & $558(18.3)$ \\
Did not answer & $92(3.0)$ \\
Profession & \\
Health Professional & $1952(63.9)$ \\
Support-clinical & $635(20.8)$ \\
Support-nonclinical & $458(15.0)$ \\
Did not answer & $11(0.4)$ \\
Region & \\
Bangkok & $224(7.3)$ \\
Central & $886(29.0)$ \\
Northern & $494(16.2)$ \\
Northeastern & $951(31.1)$ \\
Southern & $501(16.4)$ \\
Worked at HIV-focused clinic & \\
Yes & $669(21.9)$ \\
No & $2387(78.1)$ \\
Number of PLHIV provided care for during the last 12 months & \\
0 & $833(27.3)$ \\
1-4 & $901(29.5)$ \\
5-20 & $675(22.1)$ \\
>20 & $647(21.2)$ \\
\hline PLIV $=$ &
\end{tabular}

PLHIV = people living with HIV.

\subsection{Stigmatizing Attitudes toward PLHIV}

Eighty-two percent of the respondents had at least one of the four stigmatizing attitudes. When considering each issue individually, the most popular stigmatizing belief was disagreement with "women living with HIV should be allowed to have babies if they wish" (51.9\%), followed by agreement with "people get infected with HIV because they engage in irresponsible/immoral behaviors" (48.2\%), "people living with HIV should be ashamed about their HIV status" (41.3\%), and "most people living with HIV do not care that they could infect other people" (39.3\%) (Table 2).

Table 2. Stigmatizing attitudes toward PLHIV by Thai healthcare personnel $(N=3056)$.

\begin{tabular}{lc}
\hline \multicolumn{1}{c}{ Stigmatizing Attitudes } & $n \mathbf{( \% )}$ \\
\hline Women living with HIV should be allowed to have babies if they wish. (disagree) & $1586(51.9)$ \\
People get infected with HIV because they engage in irresponsible/immoral behaviors. (agree) & $1474(48.2)$ \\
People living with HIV should be ashamed about their HIV status. (agree) & $1262(41.3)$ \\
Most people living with HIV do not care that they could infect other people. (agree) & $1200(39.3)$ \\
Had at least one stigmatizing attitude & $2513(82.2)$ \\
\hline
\end{tabular}

\subsection{Correlates of Stigmatizing Attitudes}

HCP characteristics significantly associated with stigmatizing attitudes were the same in the bivariate and multivariate analyses. These included younger age, being a supportclinical or support-nonclinical staff, working in the central or northeastern region, not working at a HIV-focused clinic, and having a smaller number of PLHIV patients in the last 12 months (Table 3). 
Table 3. Factors associated with stigmatizing attitudes toward PLHIV by Thai healthcare personnel $(N=3056)$.

\begin{tabular}{|c|c|c|c|}
\hline Characteristics & $n / N(\%)$ & OR $(95 \% \mathrm{CI})$ & $\operatorname{AOR}(95 \% \mathrm{CI})$ \\
\hline \multicolumn{4}{|l|}{ Gender } \\
\hline Female & $2091 / 2546$ (82.1) & ref & \multirow{2}{*}{ a } \\
\hline Male & $421 / 508(82.9)$ & $1.05(0.82-1.36)$ & \\
\hline \multicolumn{4}{|l|}{ Age (years) } \\
\hline$<30$ & $543 / 634(85.6)$ & $1.65(1.22-2.23)$ * & $1.60(1.18-2.18)^{*}$ \\
\hline $30-39$ & $765 / 904(84.6)$ & $1.52(1.16-2.00)$ * & $1.60(1.21-2.12)$ * \\
\hline $40-49$ & $693 / 868(79.8)$ & $1.10(0.85-1.82)$ & $1.16(0.89-1.53)$ \\
\hline$\geq 50$ & $437 / 558(78.3)$ & ref & ref \\
\hline \multicolumn{4}{|l|}{ Profession } \\
\hline Health Professional & $1543 / 1952(79.0)$ & ref & ref \\
\hline Support-clinical & $556 / 635(87.6)$ & $1.87(1.44-2.42)$ * & $1.89(1.44-2.49)$ * \\
\hline Support-nonclinical & $403 / 458(88.0)$ & $1.94(1.44-2.63)$ * & $1.71(1.24-2.36)$ * \\
\hline \multicolumn{4}{|l|}{ Region } \\
\hline Bangkok & $169 / 224(75.4)$ & ref & ref \\
\hline Central & $759 / 886(85.7)$ & $1.95(1.36-2.78)$ * & $1.84(1.27-2.68)$ * \\
\hline Northern & $398 / 494(80.6)$ & $1.35(0.93-1.97)$ & $1.26(0.85-1.87)$ \\
\hline Northeastern & $789 / 951(83.0)$ & $1.59(1.12-2.25)$ * & $1.63(1.13-2.34)$ * \\
\hline Southern & $398 / 501(79.4)$ & $1.26(0.87-1.83)$ & $1.32(0.89-1.95)$ \\
\hline \multicolumn{4}{|c|}{ Currently working at HIV-focused clinics } \\
\hline Yes & $472 / 669(70.6)$ & ref & ref \\
\hline No & $2041 / 2387(85.5)$ & $2.46(2.01-3.01) *$ & $1.97(1.57-2.48)$ * \\
\hline \multicolumn{4}{|c|}{ Number of PLHIV provided care for during the last 12 months } \\
\hline 0 & $716 / 833(86.0)$ & $2.43(1.88-3.15) *$ & $1.62(1.21-2.17)$ * \\
\hline $1-4$ & $767 / 901(85.1)$ & $2.28(1.77-2.92) *$ & $1.94(1.48-2.54)$ * \\
\hline $5-20$ & $567 / 675(84.0)$ & $2.09(1.60-2.73) *$ & $1.87(1.40-2.45)$ * \\
\hline$>20$ & $463 / 647(71.6)$ & ref & ref \\
\hline
\end{tabular}

\section{Discussion}

In this nationwide probability sampled survey, $82.2 \%$ of Thai HCP had stigmatizing attitudes toward PLHIV. This rate seems very high, as participants had to have at least one stigmatizing belief for inclusion in this group, and these results should not be compared directly with the degree or strength of stigmatizing attitudes toward PLHIV as documented in other studies. This composite indicator serves as a reference point for stigmatizing attitudes among Thai HCP towards PLHIV, and can be used to determine long-term trends.

When each stigmatizing attitude is considered separately, "Women living with HIV should not allowed to have babies" was the only item in which more than half of the participants expressed negative attitudes. High levels of stigma regarding the rights of women living with HIV to have children was also found among HCP in India [24]. It was possible that HCP still perceived a high probability of mother to child HIV transmission despite the fact that actual risk in Thailand was very low due to ARV treatment [38]. It is also possible that they may anticipate that children born to HIV-affected families will have difficult lives. "People get infected with HIV because they engage in irresponsible/immoral behaviors" was the second most prevalent belief. This belief is commonly held not only by HCP $[19,20,39]$, but also by the general population $[18,40]$.

HCP whose main responsibility was related to HIV / AIDS, or who provided care to a larger number of PLHIV in the last 12 months, were less likely to have stigmatizing attitudes toward PLHIV. This was in line with studies from Iran, Lao PDR, and Italy, which found that stigmatizing attitudes were lower in HCP experienced in treating HIV / AIDS patients $[19,22,23]$. In our study, support-clinical and support-nonclinical hospital staff were more likely to have stigmatizing attitudes toward PLHIV as compared to professional 
staff. Studies from Nigeria and Iran also documented higher prevalence of stigmatizing beliefs among support staff $[8,19]$. It is likely that professional health staff do not have as many stigmatizing beliefs given that they receive more education and HIV / AIDS training. Increased age was found to be associated with less stigmatizing attitudes toward PLHIV, which was similar to other studies [19,23]. HCP in central and northeastern regions were more likely to have negative attitudes than HCP in Bangkok. This was an interesting finding which needs further investigation to verify the results and to gain a better understanding of this phenomenon.

The current study confirmed the existence of widespread stigmatizing attitudes toward PLHIV among Thai HCP. Currently, Thailand has developed and implemented interventions to address drivers of HIV-related stigma in pilot health facilities using a quality improvement approach [41]. The country also designed an online stigma reduction training program tailored to Thai HCP in the hopes of reaching more staff. These stigma reduction training programs for $\mathrm{HCP}$ include a training module addressing stigmatizing attitudes toward PLHIV. The programs are ongoing, and their effectiveness has not yet been established. Future surveillance should explore whether these interventions are effective in reducing stigmatized attitudes among Thai HCP toward PLHIV.

While older professional HCP and staff with more experience taking care of PLHIV have fewer stigmatizing attitudes toward PLHIV, they should not be excluded from participation in the stigma reduction training program. While their level of stigmatizing attitudes may be statistically significantly different from their counterparts, the rate for having at least one stigmatizing attitude was still very high. For example, $70.6 \%$ of HCP who worked at HIV-focused clinics had stigmatizing attitudes toward PLHIV as compared to $85.5 \%$ of HCP working in other departments. Selected personnel from these groups could be good peer educators or role models for the stigma reduction campaign within their healthcare facilities. Trained popular opinion leaders have been found to be effective in reducing negative attitudes among HCP [42].

The nationwide probability sampling is a strength of this study. Study participants should be a good representation of all Thai HCP. Limitations of the study included potential social desirability bias due to the negative nature of the topic. However, this was minimized by clearly communicating the anonymity of participation and provision of privacy during questionnaire completion. The fact that HIV knowledge and awareness of HIV-related stigma, the other two significant drivers of HIV-related stigma in healthcare settings, have not been studied. Information from this study alone would not be inclusive enough to design an intervention to reduce HIV-related stigma in healthcare settings. We did not record the refusals during data collection. However, the refusal rate was quite low according to feedback received from fieldwork staff. Generalizability of the study results is also limited, as the level of stigmatizing attitudes toward PLHIV and its determinants among $\mathrm{HCP}$ vary in different socio-cultural and working environments.

These surveillance surveys yield their full benefits only when conducted regularly using the same methodology and tools. Thailand has planned to conduct this survey every 2 years to document trends. Recommended future studies include HIV knowledge and awareness of HIV-related stigma. Qualitative studies to gain more understanding and identify common root causes of the stigmatizing attitudes are also needed.

\section{Conclusions}

The 2019 national surveillance survey among Thai HCP revealed prevalent stigmatizing attitudes toward PLHIV. HCP who had more work experience especially experience related to PLHIV care were less likely to have stigmatizing attitudes. These personnel could be good peer educators or role models for a stigma reduction campaign within their healthcare facilities.

Author Contributions: Conceptualization, K.S., P.K., and T.S.; methodology, K.S., P.K., J.C., and T.S.; software, J.C.; validation, K.S. and T.S.; formal analysis, K.S. and J.C.; investigation, K.S. and P.K.; resources, P.K. and T.S.; data curation, J.C.; writing—original draft preparation, K.S.; writing—review 
and editing, K.S., P.K., J.C., and T.S.; supervision, T.S.; project administration, K.S. and P.K.; funding acquisition, P.K. and T.S. All authors have read and agreed to the published version of the manuscript.

Funding: This research work was partially supported by Chiang Mai University.

Institutional Review Board Statement: The study was conducted according to the guidelines of the Declaration of Helsinki and approved by the Research Ethics Committee of Faculty of Medicine, Chiang Mai University (Certificate number 177/2019).

Informed Consent Statement: Informed consent was obtained from all subjects involved in the study.

Data Availability Statement: The data presented in this study are openly available in FigShare at https:/ / figshare.com/articles / dataset/Thailand_healthcare_HIV_stigma_survey_2019/14816271. doi: 10.6084/m9.figshare.14816271 (accessed on 21 June 2021).

Acknowledgments: We would like to thank the Thai HCP who participated in this study. We also would like to thank the staff of the Provincial Health Offices in the study areas, the Health Department of the Bangkok Metropolitan Administration, and the Office of Disease Prevention and Control in regions 1-12, who helped coordinate the data collection for this study.

Conflicts of Interest: The authors declare no conflict of interest.

\section{References}

1. UNAIDS. Reduction of HIV-Related Stigma and Discrimination; UNAIDS: Geneva, Switzerland, 2014.

2. Mahajan, A.P.; Sayles, J.N.; Patel, V.A.; Remien, R.H.; Sawires, S.R.; Ortiz, D.J.; Szekeres, G.; Coates, T.J. Stigma in the HIV / AIDS epidemic: A review of the literature and recommendations for the way forward. AIDS 2008, 22 (Suppl. 2), S67-S79. [CrossRef]

3. Greenwood, G.L.; Wilson, A.; Bansal, G.P.; Barnhart, C.; Barr, E.; Berzon, R.; Boyce, C.A.; Elwood, W.; Gamble-George, J.; Glenshaw, M.; et al. HIV-related stigma research as a priority at the national institutes of health. AIDS Behav. 2021, 1-22. [CrossRef]

4. Nyblade, L.; Mingkwan, P.; Stockton, M.A. Stigma reduction: An essential ingredient to ending AIDS by 2030. Lancet HIV 2021, 8 , e106-e113. [CrossRef]

5. UNAIDS. UNAIDS Fact Sheet on Stigma and Discrimination; UNAIDS: Geneva, Switzerland, 2003.

6. Nyblade, L.; Stangl, A.; Weiss, E.; Ashburn, K. Combating HIV stigma in health care settings: What works? J. Int. AIDS Soc. 2009, 12, 15. [CrossRef]

7. Rahmati-Najarkolaei, F.; Niknami, S.; Aminshokravi, F.; Bazargan, M.; Ahmadi, F.; Hadjizadeh, E.; Tavafian, S.S. Experiences of stigma in healthcare settings among adults living with HIV in the Islamic Republic of Iran. J. Int. AIDS Soc. 2010, 13, 27. [CrossRef] [PubMed]

8. Reis, C.; Heisler, M.; Amowitz, L.L.; Moreland, R.S.; Mafeni, J.O.; Anyamele, C.; Iacopino, V. Discriminatory Attitudes and Practices by Health Workers toward Patients with HIV/AIDS in Nigeria. PLoS Med. 2005, 2, e246. [CrossRef] [PubMed]

9. Feyissa, G.T.; Abebe, L.; Girma, E.; Woldie, M. Stigma and discrimination against people living with HIV by healthcare providers, Southwest Ethiopia. BMC Public Health 2012, 12, 522. [CrossRef]

10. Mahendra, V.S.; Gilborn, L.; Bharat, S.; Mudoi, R.J.; Gupta, I.; George, B.; Samson, L.; Daly, C.C.; Pulerwitz, J. Understanding and measuring AIDS-related stigma in health care settings: A developing country perspective. SAHARA J. Soc. Asp. HIV/AIDS 2007, 4, 616-625. [CrossRef]

11. Logie, C.H.; Lacombe-Duncan, A.; Brien, N.; Jones, N.; Lee-Foon, N.; Levermore, K.; Marshall, A.; Nyblade, L.; Newman, P.A. Barriers and facilitators to HIV testing among young men who have sex with men and transgender women in Kingston, Jamaica: A qualitative study. J. Int. AIDS Soc. 2017, 20, 21385. [CrossRef]

12. Veronese, V.; Clouse, E.; Wirtz, A.L.; Thu, K.H.; Naing, S.; Baral, S.D.; Stoové, M.; Beyrer, C. “We are not gays ... don't tell me those things": Engaging 'hidden' men who have sex with men and transgender women in HIV prevention in Myanmar. BMC Public Health 2019, 19, 63. [CrossRef]

13. Hlongwa, M.; Mashamba-Thompson, T.; Makhunga, S.; Hlongwana, K. Barriers to HIV testing uptake among men in sub-Saharan Africa: A scoping review. Afr. J. AIDS Res. 2020, 19, 13-23. [CrossRef]

14. Kinsler, J.J.; Wong, M.; Sayles, J.N.; Davis, C.; Cunningham, W.E. The effect of perceived stigma from a health care provider on access to care among a low-income HIV-positive population. AIDS Patient Care STDs 2007, 21, 584-592. [CrossRef] [PubMed]

15. Liu, Y.; Osborn, C.; Qian, H.-Z.; Yin, L.; Xiao, D.; Ruan, Y.; Simoni, J.; Zhang, X.; Shao, Y.; Vermund, S.H.; et al. Barriers and facilitators of linkage to and engagement in HIV care among HIV-positive men who have sex with men in China: A qualitative study. AIDS Patient Care STDs 2016, 30, 70-77. [CrossRef] [PubMed]

16. Reif, S.; Wilson, E.; McAllaster, C.; Pence, B. The relationship of HIV-related stigma and health care outcomes in the US deep south. AIDS Behav. 2019, 23, 242-250. [CrossRef] [PubMed]

17. Jemmott, J.B.; Zhang, J.; Croom, M.; Icard, L.D.; Rutledge, S.; O'Leary, A. Barriers and facilitators to engaging African American men who have sex with men in the HIV care continuum: A theory-based qualitative study. J. Assoc. Nurses AIDS Care 2019, 30, 352-361. [CrossRef] [PubMed] 
18. Songwathana, P.; Manderson, L. Stigma and rejection: Living with aids in villages in southern Thailand. Med. Anthr. 2001, 20, 1-23. [CrossRef]

19. Tavakoli, F.; Karamouzian, M.; Rafiei-Rad, A.A.; Iranpour, A.; Farrokhnia, M.; Noroozi, M.; Sharifi, A.; Marshall, B.D.; Shokoohi, M.; Sharifi, H. HIV-related stigma among healthcare providers in different healthcare settings: A cross-sectional study in Kerman, Iran. Int. J. Health Policy Manag. 2019, 9, 163-169. [CrossRef] [PubMed]

20. Kabbash, I.; Ali, E.A.A.; Elgendy, M.M.; Abdrabo, M.M.; Salem, H.M.; Gouda, M.R.; Elbasiony, Y.S.; Elboshy, N.; Hamed, M. HIV/AIDS-related stigma and discrimination among health care workers at Tanta University Hospitals, Egypt. Environ. Sci. Pollut. Res. 2016, 25, 30755-30762. [CrossRef]

21. Shah, S.; Elgalib, A.; Al-Wahaibi, A.; Al-Fori, M.; Raju, P.; Al-Skaiti, M.; Al-Mashani, H.N.; Duthade, K.; Omaar, I.; Muqeetullah, M.; et al. Knowledge, attitudes and practices related to HIV stigma and discrimination among healthcare workers in Oman. Sultan Qaboos Univ. Med. J. 2020, 20, 29-36. [CrossRef] [PubMed]

22. Vorasane, S.; Jimba, M.; Kikuchi, K.; Yasuoka, J.; Nanishi, K.; Durham, J.; Sychareun, V. An investigation of stigmatizing attitudes towards people living with HIV/AIDS by doctors and nurses in Vientiane, Lao PDR. BMC Health Serv. Res. 2017, 17, 1-13. [CrossRef]

23. Ledda, C.; Cicciù, F.; Puglisi, B.; Ramaci, T.; Nunnari, G.; Rapisarda, V. Attitude of health care workers (HCWs) toward patients affected by HIV/AIDS and drug users: A cross-sectional study. Int. J. Environ. Res. Public Health 2017, 14, 284. [CrossRef]

24. Ekstrand, M.L.; Ramakrishna, J.; Bharat, S.; Heylen, E. Prevalence and drivers of HIV stigma among health providers in urban India: Implications for interventions. J. Int. AIDS Soc. 2013, 16, 18717. [CrossRef] [PubMed]

25. Siraprapasiri, T.; Ongwangdee, S.; Benjarattanaporn, P.; Peerapatanapokin, W.; Sharma, M. The impact of Thailand's public health response to the HIV epidemic 1984-2015: Understanding the ingredients of success. J. Virus Erad. 2016, 2 (Suppl. 4), 7-14. [CrossRef]

26. Seekaew, P.; Pengnonyang, S.; Jantarapakde, J.; Sungsing, T.; Rodbumrung, P.; Trachunthong, D.; Cheng, C.-L.; Nakpor, T.; Reankhomfu, R.; Lingjongrat, D.; et al. Characteristics and HIV epidemiologic profiles of men who have sex with men and transgender women in key population-led test and treat cohorts in Thailand. PLoS ONE 2018, 13, e0203294. [CrossRef]

27. Kritsanavarin, U.; Bloss, E.; Manopaiboon, C.; Khawcharoenporn, T.; Harnlakon, P.; Vasanti-Uppapokakorn, M.; Kitwattanachai, P.; Naprasert, S.; Phiphatthananon, T.; Visavakum, P.; et al. HIV incidence among men who have sex with men and transgender women in four provinces in Thailand. Int. J. STD AIDS 2020, 31, 1154-1160. [CrossRef]

28. Nanthaprut, P.; Manojai, N.; Chanlearn, P.; Mattawanon, N.; Chiawkhun, P.; Homkham, N.; Traisathit, P. Comparison of HIVpositive incidence among transgender women and men who have sex with men at stand-alone and mobile voluntary counseling and testing facilities in Chiang Mai Province, Thailand. AIDS Patient Care STDS 2021, 35, 116-125. [CrossRef]

29. Jose, J.E.D.; Sakboonyarat, B.; Mungthin, M.; Nelson, K.E.; Rangsin, R. Rising prevalence of HIV infection and associated risk factors among young Thai Men in 2018. Sci Rep. 2021, 11, 1-10. [CrossRef] [PubMed]

30. HIV Info Hub. Progress towards 90-90-90 Targets. 2019. Available online: https://hivhub.ddc.moph.go.th/response.php (accessed on 4 May 2021).

31. Churcher, S. Stigma related to HIV and AIDS as a barrier to accessing health care in Thailand: A review of recent literature. WHO South East Asia J. Public Health 2013, 2, 12-22. [CrossRef] [PubMed]

32. TNP+. Index of Stigma and Discrimination against People Living with HIV/AIDS in Thailand. Bangkok: Thai Network of People Living with HIV/AIDS; TNP+: Athens, Greece, 2009.

33. Saether, S.T.; Chawphrae, U.; Zaw, M.M.; Keizer, C.; Wolffers, I. Migrants' access to antiretroviral therapy in Thailand. Trop. Med. Int. Health 2007, 12, 999-1008. [CrossRef]

34. Chan, K.Y.; Stoové, M.A.; Sringernyuang, L.; Reidpath, D.D. Stigmatization of AIDS patients: Disentangling Thai nursing students' attitudes towards HIV/AIDS, drug use, and commercial sex. AIDS Behav. 2008, 12, 146-157. [CrossRef]

35. Siraprapasiri, T.; Srithanaviboonchai, K.; Chantcharas, P.; Suwanphatthana, N.; Ongwandee, S.; Khemngern, P.; Benjarattanaporn, P.; Mingkwan, P.; Nyblade, L. Integration and scale-up of efforts to measure and reduce HIV-related stigma: The experience of Thailand. AIDS 2020, 34, S103-S114. [CrossRef] [PubMed]

36. Srithanaviboonchai, K.; Stockton, M.A.; Pudpong, N.; Chariyalertsak, S.; Prakongsai, P.; Chariyalertsak, C.; Smutraprapoot, P.; Nyblade, L. Building the evidence base for stigma and discrimination-reduction programming in Thailand: Development of tools to measure healthcare stigma and discrimination. BMC Public Health 2017, 17, 1-11. [CrossRef] [PubMed]

37. Daniel, W.W. Biostatistics: A Foundation for Analysis in the Health Sciences, 7th ed.; John Wiley \& Sons: New York, NY, USA, 1999.

38. Lolekha, R. Elimination of mother-to-child transmission of HIV-Thailand. Morb. Mortal. Wkly. Rep. 2016, 65, 562-566. [CrossRef] [PubMed]

39. Stringer, K.L.; Turan, B.; McCormick, L.; Durojaiye, M.; Nyblade, L.; Kempf, M.-C.; Lichtenstein, B.; Turan, J.M. HIV-related stigma among healthcare providers in the deep south. AIDS Behav. 2015, 20, 115-125. [CrossRef]

40. Lau, J.T.F. Discriminatory attitudes towards people living with HIV/AIDS and associated factors: A population based study in the Chinese general population. Sex. Transm. Infect. 2005, 81, 113-119. [CrossRef]

41. Ikeda, D.J.; Nyblade, L.; Srithanaviboonchai, K.; Agins, B.D. A quality improvement approach to the reduction of HIV-related stigma and discrimination in healthcare settings. BMJ Glob. Health 2019, 4, e001587. [CrossRef]

42. Feyissa, G.T.; Lockwood, C.; Woldie, M.; Munn, Z. Reducing HIV-related stigma and discrimination in healthcare settings: A systematic review of quantitative evidence. PLoS ONE 2019, 14, e0211298. [CrossRef] 